\title{
COMBINING TELETHERAPY AND ON-LINE LANGUAGE EXERCISES IN THE TREATMENT OF CHRONIC APHASIA: AN OUTCOME STUDY
}

\author{
RICHARD D. STEELE, PHD ${ }^{1}$, ALLISON BAIRD, MA, CCC-SLP², \\ DENISE MCCALL, MA, CCC-SLP ${ }^{3}$, LISA HAYNES, MS, CCC-SLP ${ }^{1}$ \\ ${ }^{1}$ LINGRAPHICA, PRINCETON, NJ, USA \\ 2 SPEECHWORKS INC., WINNIPEG, MB, CANADA \\ ${ }^{3}$ SNYDER CENTER FOR APHASIA LIFE ENHANCEMENT, BALTIMORE, MD, USA
}

\section{ABSTRACT}

We report a 12-week outcome study in which nine persons with long-term chronic aphasia received individual and group speech-language teletherapy services, and also used on-line language exercises to practice from home between therapy sessions. Participants were assessed at study initiation and completion using the Western Aphasia Battery, a portion of the Communicative Effectiveness Index, ASHA National Outcome Measurement System, and RIC Communication Confidence Rating Scale for Aphasia; additionally participants were polled regarding satisfaction at discharge. Pretreatment and post-treatment means were calculated and compared, and matched $t$-tests were used to determine significance of improvements following treatment, with patterns of independent on-line activity analyzed. Analysis of scores shows that means improved on most measures following treatment, generally significantly: the WAB AQ improved $+3.5(p=.057)$; the CETI Overall (of items administered) $-+17.8(p=.01)$, and CCRSA Overall $-+10.4(p=.0004)$. Independent work increased with time, and user satisfaction following participation was high.

Keywords: Aphasia treatment, chronic aphasia, communication confidence, functional communication, impairment, on-line exercises, outcome improvements, speech-language pathology, telemedicine, telepractice, teletherapy

There has long been interest in using distance communication technologies to serve the rehabilitation needs of persons with neurogenic communication disorders such as aphasia. The very early investigations involved telephones (e.g., Helm-Estabrooks \& Ramsberger, 1986; Vaughn, 1976). Vaughn and colleagues, for instance, explored the use of 'tel-communicology': they coupled telephones with Dictaphone recorders to assist in remote diagnosis and treatment of people with aphasia (PWA). Later, attention moved to hybrid approaches incorporating more specialized devices (e.g., Duffy et al., 1997; Wertz et al., 1992). Wertz's group, for instance, demonstrated the feasibility of combining telephones, television equipment, electronic writing pads, and other dedicated devices for the remote appraisal and diagnosis of aphasia, apraxia of speech, dysarthria, and dementia. And in more recent years, as high-speed, multimodal interconnectivity of personal computers become ever more widely available, they have become a key focus of investigations into telerehabilitation for PWA (e.g., Georgeadis et al., 2004; Hill et al., 2009; Lasker et al., 2010; Theodoros et al., 2008). Over time, this activity has produced a respectable and growing body of research reports on aphasia telerehabilitation, whose corpus was subjected to systematic review in 2013. The findings were positive - telepractice has clearly demonstrated its viability as a method of service delivery to PWA (Hall et al., 2013). Moreover, most of the research that met the survey's inclusion criteria employed the capabilities of newer, interconnected computer technologies, auguring well for their growing role in the future.

Telepractice, understood this way, involves the use of telecommunications technologies to connect a clinician with remote clients; it permits the parties at a geographic remove to interact and communicate in real time. When fully matured for these purposes, telerehabilitation applications should support all the familiar activities of traditional, in- 
person clinical service delivery, including appraisal, assessment, diagnosis, treatment, and follow-up.

There is, however, yet another way of using technology in rehabilitation - nascent, yet highly promising in that it can synergistically complement such traditional clinical therapy activities. This is the exploitation of web-based or appbased therapy exercises for independent work, which clients can access for intended purposes, on devices of their choosing, and can use whenever they like, wherever they like, and for however long they like. Their introduction involves the development and support of new, dedicated technologies - demanding tasks - so only in recent years have such offerings begun to appear. Still, the value of the approach is supported by initial studies (e.g., Cherney \& vanVuuren, 2012; Kiran et al., 2013); and over time - as designs mature, clinical effectiveness is characterized more fully, and familiarity grows - it is expected that such offerings will become ever more broadly available and widely used.

What has not been done at all to date is to combine these two uses of technology in a formally designed study. There is good reason to think that this configuration remote service delivery by a teleclinician, combined with independent client practice using assigned, high-technology therapy materials - will become an important feature of future service delivery. This model permits continued remote engagement with clients who may move away, live distantly, or travel; it reduces travel requirements on the clinician; it supports both 1-on-1 and group therapy sessions; it empowers clients to work independently between clinical sessions with a Speech-Language Pathologist (SLP) in pursuit of benefit from massed practice (Cherney et al., 2008; Pulvermüller et al., 2001); it allows SLPs remotely to review client activity with assigned materials and modify associated treatment plans; and it enables clinicians to adjust the balance of face-to-face therapy vs. independent on-line work adaptively to exploit synergies between the two. All these considerations suggest that this technologically-enriched service delivery model merits further investigation. Motivated by these considerations, the authors designed and executed the following study with two complementary, overarching goals: first, to demonstrate the practical feasibility using this model to deliver therapeutic services to persons with chronic aphasia; and second, to establish and begin characterizing the clinical and other benefits of such service delivery.

\section{METHODS}

\section{OVERVIEW}

As a feasibility study, we first were looking at whether service delivery via such technology channels is - in practice - doable; and second, whether the quality of such services is adjudged to be satisfactory by the participants. Technical contraindications to approach viability comprise: (i) inadequate audio- or video-quality to support remote therapy; (ii) unworkable connectivity for therapeutic purposes; or (iii) practical inoperability of the equipment by participants. Psychological contraindications comprise dissatisfactions that lead one or more participants to abandon participation prematurely.

As an outcome study, we were seeking to answer the question, 'Did participants improve significantly by the end of the study?' For assessments, we employed established and familiar instruments that were designed for aphasia. Subjects were scored at the study's start, and again at the study's end; the resultant data were analyzed to study patterns of outcome changes (Frattali, 1998).

\section{SUBJECTS}

All subjects were adults with a medical diagnosis of aphasia, enrolled at the Snyder Center for Aphasia Life Enhancement (SCALE) in Baltimore, MD. SCALE is one of a number of community-based treatment centers that operate according to the principles of the Life Participation Approach to Aphasia (LPAA; Chapey et al., 2001); its staff is experienced in promoting successful technology use by PWA (McCall, 2012). To identify subjects for participation in this study, we employed the following inclusion criteria: (i) assignment to one of the aphasia diagnostic categories upon intake administration of the Western Aphasia Battery; (ii) chronicity of aphasia, defined as study participation starting at least 6 months post-onset for each subject; (iii) willingness to participate in study activities throughout its 12 week course; and (iv) Internet connectivity at home adequate to support study activities. Altogether, nine SCALE members were identified who met these criteria. After receiving - both verbally and in accessible written form - a description of study activities and expectations, plus risks and benefits of participation, these nine elected to participate; and they comprise the sample of this study. Table 1 demographically and clinically characterizes these subjects individually, and Table 2 provides a summary overview of these data. 
Table 1. Subjects at SCALE Center $(n=9)$

\begin{tabular}{|c|c|c|c|c|c|c|c|c|c|c|c|c|}
\hline \multirow[t]{2}{*}{ ID } & \multirow[t]{2}{*}{ Etiology } & \multirow{2}{*}{$\begin{array}{c}\text { Aphasia } \\
\text { type }\end{array}$} & \multirow[t]{2}{*}{ Gender } & \multirow[t]{2}{*}{ Age } & \multirow[t]{2}{*}{$\mathrm{I} / \mathrm{r}$} & \multirow{2}{*}{$\begin{array}{l}\text { Years } \\
\text { post- } \\
\text { onset }\end{array}$} & \multirow{2}{*}{$\begin{array}{c}\text { Years } \\
\text { at } \\
\text { SCALE }\end{array}$} & \multicolumn{5}{|c|}{ Assessments } \\
\hline & & & & & & & & $\begin{array}{c}\text { WAB- } \\
\text { R }\end{array}$ & CETI & NOMS & CCRSA & USS \\
\hline GB1 & L-CVA & trans. mot & $f$ & 77 & $r$ & 19.2 & 0.67 & $\mathrm{X}$ & $\mathrm{X}$ & $X$ & $X$ & $\mathrm{X}$ \\
\hline JG3 & L-CVA & Broca's & $\mathrm{m}$ & 43 & $r$ & 3.8 & 2.75 & $X$ & $\mathrm{X}$ & $X$ & $\mathrm{X}$ & $\mathrm{X}$ \\
\hline DL4 & L-CVA & Broca's & $\mathrm{m}$ & 67 & $\bullet$ & 6.2 & 2.42 & $\mathrm{X}$ & $\bullet$ & $\mathrm{X}$ & $\mathrm{X}$ & $\mathrm{X}$ \\
\hline KM5 & L-CVA & Broca's & $\mathrm{m}$ & 53 & $\mathrm{a}$ & 1.7 & 0.08 & $\mathrm{X}$ & $\mathrm{X}$ & $\mathrm{X}$ & $\mathrm{X}$ & $\mathrm{X}$ \\
\hline DS8 & L-CVA & conduction & $\mathrm{m}$ & 71 & $r$ & 2.9 & 1.42 & $\mathrm{X}$ & $X$ & $\mathrm{X}$ & $X$ & $X$ \\
\hline DW9 & L-CVA & Broca's & $\mathrm{m}$ & 62 & 1 & 8.3 & 4.42 & $X$ & $\mathrm{X}$ & $\mathrm{X}$ & $\mathrm{X}$ & $\mathrm{X}$ \\
\hline
\end{tabular}

Note. WAB-R: Western Aphasia Battery-Revised; CETI: Communication Effectiveness Index (portion administered in Appendix A); NOMS: ASHA National Outcomes Measurement System; CCRSA-RIC: Communication Confidence Rating Scale for Aphasia (items in Appendix B); USS: User Satisfaction Survey (items in Appendix C)

\section{Table 2. Demographic/Clinical Data Summary for SCALE Participants with Chronic Aphasia}

\begin{tabular}{|c|c|c|c|}
\hline$\underline{\text { Characteristic }}$ & Mean (SD) & $\underline{\text { Range }}$ & №. $(\%)$ \\
\hline $\begin{array}{l}\text { Gender } \\
\text { male } \\
\text { female }\end{array}$ & & & $\begin{array}{ll}7 & (77.8) \\
2 & (22.2)\end{array}$ \\
\hline Age (y) & $61.4 \quad(10.4)$ & $43-77$ & $9(100.0)$ \\
\hline $\begin{array}{l}\text { Handedness } \\
\text { right } \\
\text { left } \\
\text { ambidextrous }\end{array}$ & & & $\begin{array}{ll}7 & (77.8) \\
1 & (11.1) \\
1 & (11.1)\end{array}$ \\
\hline Time post-onset $(\mathrm{y})$ & $5.57 \quad(5.63)$ & $1.3-19.2$ & $9(100.0)$ \\
\hline $\begin{array}{l}\text { Etiology } \\
\text { L-CVA } \\
\text { unknown }\end{array}$ & & & $\begin{array}{ll}8 & (88.9) \\
1 & (11.1)\end{array}$ \\
\hline $\begin{array}{l}\text { Aphasia diagnostic cate } \\
\text { Broca's } \\
\text { transcortical motor } \\
\text { conduction } \\
\text { isolation } \\
\text { Wernicke's }\end{array}$ & ries at intake ( & & $\begin{array}{ll}5 & (55.5) \\
1 & (11.1) \\
1 & (11.1) \\
1 & (11.1) \\
1 & (11.1)\end{array}$ \\
\hline $\begin{array}{l}\text { Overall assessment lev } \\
\text { WAB AQ } \\
\text { CETI Overall } \\
\text { NOMS Overall (\%) } \\
\text { CCRSA Overall }\end{array}$ & $\begin{array}{l}\text { at intake } \\
54.4(9.8) \\
49.9(18.6) \\
43.5(7.4) \\
64.9(12.1)\end{array}$ & $\begin{array}{l}42.5-68.6 \\
24.3-79.0 \\
31.4-54.3 \\
52.0-82.2\end{array}$ & $\begin{array}{ll}9 & (100.0) \\
8 & (88.9) \\
9 & (100.0) \\
7 & (77.8)\end{array}$ \\
\hline Years at SCALE & $1.66(1.41)$ & $0.08-4.42$ & $9(100.0)$ \\
\hline $\begin{array}{l}\text { Teletherapy Treatment } \\
\text { frequency (sess/wk) } \\
\text { duration (wks) }\end{array}$ & $\begin{array}{ll}1.75 & (0) \\
12.0 & (0)\end{array}$ & $\begin{array}{l}\text { no variation } \\
\text { no variation }\end{array}$ & $\begin{array}{ll}9 & (100.0) \\
9 & (100.0)\end{array}$ \\
\hline
\end{tabular}




\section{PARTICIPATION SCHEDULE}

The study was designed for completion in 12 weeks, divided into three periods of four weeks each. The initial weeks of each period - i.e., weeks 1, 5, and 9 - were devoted to remote individual therapy sessions. These took place in subjects' homes, ran for an hour each, and were scheduled at times mutually convenient for subject and treating clinician. The nine remaining weeks - i.e., weeks 2 4, 6-8, and 10-12 - were devoted to remote group therapy sessions, which took place in SCALE meeting rooms and ran for an hour each. Subjects participated in these remote group sessions with 3 or 4 other participants twice a week, on Mondays and Wednesdays, with group composition varying slightly according to day in accommodation of subjects' other SCALE activities. Each subject thus received 3 hours of individual therapy plus 18 hours of group therapy, to yield a combined total of 21 hours of remote therapy over 12 weeks.

\section{STUDY LOGISTICS}

The study was conducted by personnel dispersed geographically across the US and Canada. The first author worked from Washington State to oversee conceptual planning of the study, to host weekly teleconference calls for status updates and activities discussions, and to maintain and update minutes for general reference via the web-based project-management tool Basecamp. The second author served as teleclinician, providing remote therapeutic service delivery from her company's clinic in the province of Manitoba; she also maintained treatment records available for general review by all personnel, using Basecamp on the Internet. The third author coordinated all clinical activities at SCALE from the state of Maryland, and oversaw collection and reporting of the pre- and post-treatment assessment data for outcome analyses. The fourth author worked in New Jersey, participating in clinical planning, reviewing interim results, and coordinating with other office personnel as required. Technical support for the remote group therapy sessions and remote individual therapy sessions was provided by two technology specialists located in New Jersey; and two on-site assistants in the SCALE facility in Maryland provided services to maintain high-quality connectivity during group therapy, and services within group sessions as an SLP-Assistant.

\section{TECHNOLOGIES EMPLOYED}

During this pilot study, we utilized two commercially available services to host remote therapy sessions - WebEx and GoToMeeting. The purpose of comparing alternative services was to try to identify which features work well and which poorly for providing therapy service remotely, with the intention ultimately of building our own platform for web- based therapy service delivery. We found that - with effort - both services could be pressed into service for remote therapy delivery, but that neither was particularly well suited to serving our audience. For example, we learned that it is important to be able to see the faces of all participants continuously, because facial expressions are natural supports of communication that may be used by people with aphasia. WebEx permits viewing of all participants as long as screen-sharing is avoided; but once screen-sharing is invoked, then only the face of the current speaker is displayed. GoToMeeting worked better in this instance, permitting uninterrupted views of all participants' faces while screen-sharing; and this capability will be built into our ultimate delivery platform as well. In terms of audio quality, in contrast, WebEx was found to perform better than GoToMeeting, which less consistently suppressed echo effects that are disruptive to speakers and confusing to clients.

For asynchronous communications among project staff, e-mail and the web-based project-management tool Basecamp were used. They enabled the geographically dispersed staff to coordinate activities, maintain updated records, share written documents, and host on-line discussions. For weekly real-time conference meetings of this same geographically dispersed staff, GoToMeeting was employed and found fully adequate for our needs.

For completion of homework assignments, and for any additional, independently and volitionally pursued practice and exercise, participants could whenever convenient access the TalkPath suite of on-line exercises, using either the browsers on computers in their home, or using apps that had been downloaded onto their personal iPads. Exercises were identical regardless of the platform employed, and all activities using TalkPath materials were recorded and archived on the web servers, for subsequent access and analysis.

Prior to the launch of the study, each of the nine participants received on loan identical laptop computers specifically current Lenovo models - onto which all projectcritical software had been preloaded. The purpose was to ensure consistency of hardware platforms and software installations on the equipment that subjects would be using through the study. Our experience is that such consistency markedly simplifies the provision of remote technical assistance, whenever needed, for all participants.

\section{GROUP THERAPY SESSIONS}

Conduct of group therapy sessions delivered remotely was based on the teleclinician's experiences in providing effective group therapy traditionally, with all participants sitting around a table. Such group therapy has been shown to be both efficacious and beneficial (Elman, 2007; Elman \& Bernstein-Ellis, 1999). Group teletherapy goals included: (i) 
stimulating word finding in aphasia; (ii) increasing speech intelligibility in the presence of dysarthria, apraxia of speech, or phonological errors; (iii) training conventional social language exchanges; (iv) training sentences of increasing length and complexity; (v) increasing turns in conversation with the end goal of increasing engagement in conversations relevant to the client; (vi) fostering a sense of well-being so feelings of confidence and belonging are enhanced; and (vii) increasing life participation outside of therapy in areas of importance to the client. Activities during sessions were kept varied, and adjusted to individual subject abilities and potential as therapeutically indicated.

Regardless of aphasia type or severity, participants in groups were expected, encouraged, and prompted to interact with one another using spoken language.

Greetings, introductions, and asking personal questions were all targeted in group therapy. Participants took turns discussing their activities during the week, with elaborations encouraged. Sentence patterning (Naeser, 1975) and response elaboration training (Gaddie et al., 1991; Kearns, 1985) were used to promote exchanges that were complete, correct, and intelligible. Individualized goals and topics of interest were targeted as client strengths were revealed.

\section{1-ON-1 THERAPY SESSIONS}

Individual sessions were designed to reveal communicative competence, areas to be targeted in group therapy, and the preferences and interests of the client. Essentially, the clinician used this time to establish a successful communicative relationship with the client that was in turn leveraged to promote clients' conversations with others. Conversations were meant to be lively and relevant with reduced emphasis on word finding difficulties.

Principles of Supported Conversation (Alarcon \& Rogers, 2012; Kagan, 1998), liberally exploiting typing displays, were used to maintain flow in conversations. This approach included typing all key utterances the clinician and client said, as well modeling appropriate responses to questions and requiring the client to repeat the response. In addition, principles of script training (Lee et al., 2009; Youmans et al., 2005), sentence patterning, and response elaboration were freely exploited as useful. Scripts were intermittently developed with clients during individual sessions, and these were then presented to others during group sessions.

\section{INDEPENDENT ON-LINE THERAPY}

All participants' TalkPath activities, whether assigned or not, were reviewed with clients during 1-on-1 sessions; follow-on homework activities were assigned for clients' upcoming free time; and the completion of such assignments was strongly encouraged before wrapping up every session. Parallels between homework compliance and successful communication in the group context were identified and stressed. Clients were educated on the effects of neuroplasticity on recovery, on the importance of the right homework at the right time, and on the benefits of massed practice. Behind the scenes, detailed logs of users' activity were kept on TalkPath's Web server; and analyses of the data gathered in that way permitted the investigators to calculate the frequency of use, duration of sessions, intensity of activity, and patterns of performance change over time.

With regard to content, TalkPath exercises address four areas of especial importance for PWA, namely, listening, speaking, reading, and writing. Within each domain, there are choices of activity types and activity challenge levels; and - upon execution - various hints are provided upon user request, to promote successful performance. TalkPath also supports a supervisory mode for the treating clinicians, which permits them remotely and at will to review performance and alter assignments. These latter capabilities proved invaluable in tracking clients' progress, keeping them engaged, and adapting as subjects improved and new opportunities presented themselves.

\section{TALKPATH USES DURING CLINICAL SESSIONS}

In addition to providing independent practice opportunities for participants between clinical sessions, TalkPath exercises were also employed by the teleclinician during teletherapy sessions. In the sessions with groups, such use occurred primarily early on, and focused on introducing exercises, demonstrating use, and emphasizing the importance of massed practice. In contrast, TalkPath utilization during 1-on-1 sessions was more evenly spread over the 12-week period. Its use during sessions, however, was not generally of long duration: rather, a short initial period of diagnostic therapy with TalkPath was employed to help shape the rest of the session, which - as noted above - employed more traditional strategies to increase success in functional communication. TalkPath exercises were useful for these purposes in several ways. First, they provided structured materials to probe clients' strengths and weaknesses in specific tasks across a range of challenge levels. Second, they could reveal to clients available competencies of which they themselves were unaware. Third, they provided the arsenal of practice materials, available in reserve as homework assignments, which participants could use to improve in skills of identified utility. Together, these informed and advanced participants' expectations regarding reachable levels of functional communication, ways to target constituent skills, tools to improve their mastery, and strategies for exploiting them communicatively. 


\section{ASSESSMENT INSTRUMENTS}

Participants were administered several assessments at the project's start and end to study changes following treatment on: (i) impairment levels, in specific speech / language modalities; (ii) functional communication; (iii) levels of SLP cueing required to elicit correct subject responses; and (iv) clients' self-reported communicative confidence. In addition, participants completed a custom User Satisfaction Survey at the end of the study.

To study changes at the impairment level, we used the Western Aphasia Battery-Revised (WAB-R; Kertesz, 2006), adapted from the predecessor Western Aphasia Battery (WAB; Kertesz, 1982). The WAB-R is a useful, well regarded, and widely employed standardized assessment instrument of impairment: it has been psychometrically characterized and shown to be valid and reliable (Shewan \& Kertesz, 1984). Its sections address the modalities of Spontaneous Speech, Auditory Verbal Comprehension, Repetition, Naming, Reading, and Writing; and it permits calculation of an Aphasia Quotient (AQ), an overall metric of aphasia severity. The WAB-R is widely used by speechlanguage pathologists to evaluate changes in language following treatment.

To investigate changes in functional communication, we administered 10 items of the 16 item Communicative Effectiveness Index (CETI). Like the WAB-R, the CETI is an established, useful, and standardized assessment instrument, of documented validity and reliability (Lomas et al., 1989). It was created specifically to assess communicative performance in situations of importance to PWA, and designed to be sensitive to changes between two points in time. It is usually completed by a family member or long-time friend of the PWA. Appendix A lists the items that were rated.

To study types of SLP cueing required for successful subject performance before and after treatment, we used the National Outcomes Measurement System (NOMS) ratings, developed by the American Speech-LanguageHearing Association. For this study, we used specifically the NOMS Adult Disorders material (ASHA, 2003), selecting five areas central to PWA - motor-speech performance, speaking, listening, reading, and writing. Its ratings are completed by the treating SLP clinician.

To investigate subjects' confidence in their own communicative abilities, we used the Communication Confidence Rating Scale for Aphasia from the Rehabilitation Institute of Chicago (CCRSA-RIC; Babbitt et al., 2011, Cherney et al., 2011). This instrument registers on a tenpoint scale self-reported degrees of communicative confidence in activities of identified interest to PWA. For reference, Appendix B lists its 10 activities.
To gauge participants' satisfaction following completion of this work, we developed a custom User Satisfaction Survey. It contained 27 questions, organized around four areas of interest to us, namely, satisfaction with: (i) group therapy delivered by a clinician using distance communication technologies; (ii) individual therapy delivered by a clinician using distance communication technologies; (iii) independent work by participants using the on-line therapy materials; and (iv) properties of the relationship established with the teletherapist. Responses were captured on a scale running from 1 (least satisfactory) to 5 (most satisfactory). For reference, the 27 items organized into the four interest areas are listed in Appendix C.

\section{DATA ANALYSIS}

Raw data were entered into the Data Desk® application for statistical and exploratory data analysis (Hatch \& Farhady, 1982; James, 1998; Tukey, 1977). Our focus here was within-subject changes, to compare the performance of study subjects before and after program participation. To investigate the change over time, we calculated the existence, magnitude, and direction of the difference of means between before- and after-program scores, and then established the statistical significance of those differences using matched t-tests. This was done for data from the impairment level assessments, functional communication scores, NOMS ratings, and communication confidence responses. Finally, to give a broader perspective, we compared the improvement patterns documented in this study with patterns found earlier in similar - but not identical - predecessor treatment programs.

\section{RESULTS}

\section{IMPAIRMENT-LEVEL OUTCOMES}

As Table 3 shows, outcome analyses of subjects' WAB mean scores showed changes that were mostly modest in magnitude - representing low single-digit percentage improvements - and not statistically significant. This holds most obviously for performance changes in 'Spontaneous Speech' (+0.9, out of 20; $p=.18)$, 'Auditory Verbal Comprehension' ( -1.9 , out of 200 ; = .55), 'Repetition' (+ 5.9 , out of $100 ; p=.102)$, and 'Naming' (+3.7, out of $100 ; p$ $=.25)$. In this context, the change in the calculated 'Aphasia Quotient' is noteworthy: it showed a modest improvement (+ 3.5 , out of 100 ) that is additionally coupled with a strong trend towards significance $(p=.057)$. 
Table 3. WAB-R (Impairment Level) Changes in SCALE Participants with Chronic Aphasia following Remote Therapy \& On-line Exercise

\begin{tabular}{|c|c|c|c|c|c|c|}
\hline Item & $\mathrm{n}$ & Initial Mean (SD) & Final Mean (SD) & Diff (SD) & tobs & $\underline{p}$ \\
\hline \multicolumn{7}{|l|}{ Spontaneous } \\
\hline speech & 9 & $10.1(2.5)$ & $11.0(2.4)$ & $+0.9(1.8)$ & +1.46 & $=.18$ \\
\hline \multicolumn{7}{|l|}{ Aud. verb. } \\
\hline comprehen. & 9 & $140.0(34.6)$ & $138.1(35.1)$ & $-1.9(9.1)$ & -0.62 & $=.55$ \\
\hline Repetition & 9 & $49.5(20.4)$ & $55.4(15.9)$ & $+5.9(9.6)$ & +1.85 & $=.102$ \\
\hline Naming & 9 & $49.0(16.0)$ & $52.7(16.9)$ & +3.7 (8.8) & +1.25 & $=.25$ \\
\hline Aphasia $†$ & 9 & $53.9 \quad(9.4)$ & $57.4(10.4)$ & $+3.5 \dagger(4.7)$ & +2.22 & $=.057 \dagger$ \\
\hline
\end{tabular}

$\overline{\dagger P<.10}$

\section{FUNCTIONAL COMMUNICATION OUTCOMES}

As shown in Table 4, on the 10 CETI items rated, subjects markedly improved their functional communication scores following treatment. In nine of the 10 items administered, the changes represent double-digit absolute percentage improvements that are statistically significant: their improvement magnitudes range from +27.1 to +11.1 (out of a total of 100). In the remaining two cases - Items \#1 and \#6 - the changes are substantial improvements that show a trend towards significance.

Table 4. CETI (Functional Communication) Changes in SCALE Participants with Chronic Aphasia Following Remote Therapy and On-line Exercise

\begin{tabular}{|c|c|c|c|c|c|c|}
\hline CETI & $\underline{\mathrm{n}}$ & Initial Mean (SD) & Final Mean (SD) & Diff (SD) & tobs & $\underline{p}$ \\
\hline \#1† & 8 & $82.6(17.3)$ & $91.1(11.1)$ & $+8.5 \dagger(11.0)$ & +2.18 & $=.066$ \\
\hline$\# 2$ * & 8 & $41.6(22.3)$ & $61.1(17.3)$ & $+19.5^{\star} \quad(9.8)$ & +3.60 & $=.009$ \\
\hline$\# 3$ * & 8 & $64.4(22.9)$ & $75.5(21.6)$ & $+11.1^{*}(6.0)$ & +5.22 & $=.001$ \\
\hline$\# 4^{*}$ & 8 & $48.4(30.0)$ & $70.6(19.5)$ & $+22.3^{*}(26.3)$ & +2.39 & $=.048$ \\
\hline$\# 5^{*}$ & 8 & $60.8(24.0)$ & $78.8(18.7)$ & $+18.0^{\star}(15.0)$ & +3.39 & $=.012$ \\
\hline$\# 6 \dagger$ & 8 & $46.9(27.8)$ & $64.9(18.5)$ & $+18.0 \dagger(24.6)$ & +2.07 & $=.078$ \\
\hline$\# 7$ & • & $\cdot$ & $\cdot$ & - & $\cdot$ & • \\
\hline$\# 8$ & • & • & • & - & - & • \\
\hline$\# 9$ * & 8 & $66.9(25.9)$ & $84.0(12.3)$ & $+17.1^{*}(18.8)$ & +2.58 & $=.036$ \\
\hline$\# 10$ * & 8 & $28.6(22.9)$ & $55.7(11.8)$ & $+27.1^{*}(22.0)$ & +3.48 & $=.010$ \\
\hline$\# 11$ & - & $\bullet$ & - & • & • & - \\
\hline$\# 12$ & - & $\bullet$ & $\bullet$ & $\bullet$ & • & $\bullet$ \\
\hline$\# 13$ & • & • & • & • & • & • \\
\hline$\# 14$ & • & • & • & • & • & • \\
\hline$\# 15$ * & 8 & $36.6(29.0)$ & $54.9(24.6)$ & $+18.3^{*}(19.4)$ & +2.66 & $=.033$ \\
\hline$\# 16$ * & 8 & $21.3(23.4)$ & $40.1(22.0)$ & $+18.8^{\star}(14.2)$ & +3.73 & $=.007$ \\
\hline $\begin{array}{c}\# 1-16{ }^{*} \\
\text { Overall }\end{array}$ & 8 & $49.9(18.6)$ & $67.7(13.6)$ & $+17.8^{\star}(14.7)$ & +3.44 & $=.011$ \\
\hline
\end{tabular}




\section{NOMS OUTCOMES}

The NOMS assessments showed a pattern of change that was - mostly - more robust than changes at the impairment level, but less robust than changes at the functional communication level. As Table 5 shows, on four of the five NOMS items rated - namely, motor speech, verbal comprehension, speaking, and reading - subjects' mean-score changes revealed improvements that were modest in magnitude - less than 1 point - but nonetheless statistically significant. On the fifth item - writing - the clinician reported no change at discharge owing to technical difficulties in documenting any changes that may have occurred; this thus becomes an item for attention in future technology development.

Table 5. ASHA-NOMS Changes in SCALE Participants with Chronic Aphasia following Remote Therapy \& On-line Exercise

\begin{tabular}{|c|c|c|c|c|c|c|}
\hline$\underline{\text { Item }}$ & $\underline{\mathrm{n}}$ & Initial Mean (SD) & Final Mean (SD) & $\underline{\text { Diff (SD) }}$ & $\underline{\text { tobs }}$ & $\underline{p}$ \\
\hline Motor speech & 9 & $3.2(0.7)$ & $4.1(0.6)$ & $+0.9^{*}(0.4)$ & +6.01 & $=.0003$ \\
\hline Vrb. Comp.* & 9 & $3.6(0.7)$ & $4.1(0.7)$ & $+0.5^{*}(0.5)$ & +3.27 & $=.01$ \\
\hline Speaking * & 9 & $3.2(0.7)$ & $3.8(0.5)$ & $+0.6^{*}(0.4)$ & +3.77 & $=.006$ \\
\hline Reading * & 9 & $3.0(0.7)$ & $3.4(0.5)$ & $+0.4^{*}(0.4)$ & +3.03 & $=.02$ \\
\hline Writing & 9 & $2.2(0.4)$ & $2.2(0.4)$ & $(0.0)$ & 0.0 & $=1.0$ \\
\hline
\end{tabular}

\section{COMMUNICATION CONFIDENCE OUTCOMES}

Table 6 shows the changes in subjects' self-rated confidence levels, in the 10 investigated communicative situations. The results are interesting. On five of the 10 rated items - \#1, \#2, \#3, \#4, and \#9-changes are improvements that fail to reach statistical significance: these range from small $(+0.9)$ to large $(+11.1)$. On four other items - \#5, \#6, \#8, and \#10 - the changes are substantial improvements that show a trend towards significance. On Item \#7 - "How confident are you that people include you in conversations?" - self-confidence ratings following treatment rose from 42.1 to 55.7 , an improvement of $+13.6^{*}$ $(p=.009)$. The group's Overall Confidence Level averaging over all the assessed communicative situations likewise improved greatly following treatment $\left(+10.1^{*}\right.$, out of $100 ; p=.0004)$.

Table 6. RIC - CCRSA (Communicative Confidence) Changes in SCALE Participants with Chronic Aphasia Following Remote Therapy and On-line Exercise

\begin{tabular}{|c|c|c|c|c|c|c|c|}
\hline CCRSA & & $\underline{\mathrm{n}}$ & Initial Mean (SD) & Final Mean (SD) & Diff (SD) & tobs & $\underline{p}$ \\
\hline$\# 1$ & & $\overline{7}$ & $69.3(23.5)$ & $76.0(23.1)$ & $\begin{array}{ll}+6.7 \quad(37.1) \\
\text { (3) }\end{array}$ & $\overline{+0.48}$ & $=.64$ \\
\hline$\# 2$ & & 7 & $67.8(28.3)$ & 76.4 (19.3) & $+8.6 \quad(16.5)$ & +1.37 & $=.22$ \\
\hline \# 3 & & 7 & $94.8 \quad(6.8)$ & $95.7 \quad(6.1)$ & +0.9 & +1.22 & $=.27$ \\
\hline$\# 4$ & & 7 & $87.2(22.1)$ & $90.9(13.9)$ & +3.7 (10.6) & +0.93 & $=.39$ \\
\hline \# 5 & $\dagger$ & 7 & $49.3(36.1)$ & $58.7(34.2)$ & $+9.4 \dagger(14.7)$ & +2.12 & $=.078$ \\
\hline \# 6 & $\dagger$ & 7 & $57.1(30.4)$ & $71.1(20.6)$ & $+14.0 \dagger(17.2)$ & +2.15 & $=.075$ \\
\hline \# 7 & * & 7 & $42.1(29.7)$ & $55.7(30.8)$ & $+13.6^{*}(9.5)$ & +3.78 & $=.009$ \\
\hline$\# 8$ & $\dagger$ & 7 & $55.7(27.0)$ & $78.6(17.7)$ & $+22.9 \dagger(27.4)$ & +2.21 & $=.069$ \\
\hline$\# 9$ & & 7 & $76.5(18.0)$ & $87.6(17.2)$ & $+11.1 \quad(18.4)$ & +1.65 & $=.16$ \\
\hline$\# 10$ & $\dagger$ & 7 & $49.6(16.8)$ & $60.0(24.2)$ & $+10.4 \dagger(11.5)$ & +2.39 & $=.054$ \\
\hline$\# 1-10$ & & 7 & $65.0(12.1)$ & $75.1(12.0)$ & +10.1 & +7.05 & $=.0004$ \\
\hline
\end{tabular}

$\overline{{ }^{*} p<.05 ; \quad \dagger p}<.10$ 


\section{SATISFACTION RATINGS}

Here we used a User Satisfaction Survey (USS) of our own construction: Appendix $\mathrm{C}$ lists its items, and Table 7 displays results. These satisfaction ratings differ from the results above in that they are not outcome measures that analyze differences in scores recorded at intake and discharge. Rather, the satisfaction surveys were completed by participants only once - at the end of the study - after they had gained the experiences on which to base their judgments. Their value lies in identifying where user satisfaction is particularly high or particularly low, and in using that information to guide efforts to improve the user experience by adjusting offerings over time. Responses showed that - overall - user satisfaction with program participation was distinctly high: on a scale of 1 (least satisfied) to 5 (most satisfied), mean response over all items was slightly less than 4.3. When broken down by query domain, however, it emerges that remote work with a live therapist is more satisfactory than independent work using on-line therapy materials. The mean score for 'remote 1-on1 therapy' was 4.40; the mean score for 'remote group therapy' was 4.33; the mean score for the experience of 'working remotely with an SLP' was 4.35; in contrast, the mean score for 'working independently with web-based therapy materials' was a lower 4.02.

Table 7. User Satisfaction Levels in SCALE Participants with Chronic Aphasia at Conclusion of Remote Therapy and On-line Exercise

Domain / Sub-Items

Remote Group Tx

\#1

\# 2

\# 3

\# 4

\# 5

\# 6

\# 7

Remote 1-on-1 Tx

\section{\# 8}

\# 9

\#10

$\# 11$

\#12

\#13

\#14

Web-based Exercises

\#15

\#16

\#17

\#18

\#19

\#20

\#21

Remote Work c SLP

\#22
\#23
\#24
\#25
\#26
\#27

\#22

\#23

\#25

\#26

\#27
Mean (SD)

4.33 (0.38)

4.63

4.06

4.13

3.88

4.38

4.21

5.00

$4.40(0.21)$

4.50

4.50

4.63

4.31

4.56

4.31

4.00

$4.02(0.44)$

4.44

3.75

3.80

4.50

3.50

3.63

4.50

4.35 (0.33)

4.25

4.67

4.28

3.78

4.63

4.47
Range

3.88-5.00

4.0-5.0

1.0-5.0

3.0-5.0

2.0-5.0

2.0-5.0

4.0-5.0

no variation

4.00-4.63

4.0-5.0

1.0-5.0

3.0-5.0

4.0-5.0

3.5-5.0

3.5-5.0

1.0-5.0

3.50-4.50

3.5-5.0

3.0-4.0

3.0-5.0

3.0-5.0

2.0-5.0

1.0-5.0

3.0-5.0

3.78-4.67

4.0-5.0

4.0-5.0

4.0-5.0

3.0-4.7

4.0-5.0

3.0-5.0
№. (\%)

8 (88.9)

“ “

"

" “

" “

" "

“ “

8 (88.9)

" “

" “

“ "

" "

" “

" "

“ “

8 (88.9)

" “

$5 \quad(55.5)$

8 (88.9)

"

" "

8 (88.9)

" "

" "

“ “

“ "

" "

“ “

@ 3 subjects reported being unaware they could select their own exercises

Note. Scale Key: $1=$ least satisfied to $5=$ most satisfied 


\section{ANALYSIS OF DATA FROM ON-LINE USAGE LOGS}

Presently, we offer tools that report basic usage data for individual users. On our website, reports are automatically generated that display user on-line activity as detailed lists of sequential interface actions, accompanied by bar graph comparing activity levels in the four domains of Reading/Writing/Listening/Speaking. Table 8 provides an illustrative example of such a list in $8 \mathrm{~A}$, and additionally shows ways in which those data can be further organized, analyzed and displayed for clinical reference and use in 8B. The additional tools for such advanced automated uses of log data are currently in development.

The sequential listings are typically displayed in long lists that allow clinicians and researchers to inspect user performance in close detail. In the example here, we can see that the user completed the four illustrative items quickly (average completion time is 17.5 seconds), accurately (all four listed examples show correct responses), independently (no cues were used), and independent of grammatical category (noun, verb, adjective, pronoun). These data suggest that the user can perform the reading tasks at this challenge level competently.

The overview provided in the 'Daily Report' of $8 \mathrm{~B}$ complements and enriches the previous understandings. We see that the task above - Reading Word ID - occupied only $11 \%$ of the total work time that day; and that a complementary Listening Word ID task occupied only an additional $7 \%$ of the work time, also with high levels of performance accuracy. In contrast, a Reading Matching task occupied $30 \%$ of the user's time that day, and that many cues - 15 in all - were activated by the user in support of successful performance. From this it appears that GB1 is - either consciously or subconsciously allocating greater time and effort to tasks that present a higher level of challenge. Such behavior would be consonant with experiencing successes as more satisfying; and this working hypothesis might then reward further clinician attention.

Finally, when a series of such 'Daily Reports' are compiled and compared, we can see patterns emerge over time. Preliminary analysis of this type shows that user GB1 exhibited general patterns of increased engagement over time with on-line exercises, appearing in general patterns that were occasionally interrupted. Specifically, absolute time spent completing on-line therapy tasks tends to rise week over week; the number of different types of activities activated tends to grow as time progresses; and a tendency to move toward greater balance among four primary domains - Reading, Writing, Listening, and Speaking - is discernable. Subsequent analyses, using comparable data from the other study participants, will help establish how frequently such patterns are observed in PWA more generally.

Table 8. On-Line Activity Log Data (illustrative samples)

\section{A. User Activity Data in Automatically Generated Lists}

User: GB1

Tuesday, March 11, 2014

Total Work Time: 55 minutes

Reading: Word ID, 2:16 PM

Instructions spoken? (n) Stimulus spoken? (n) Choices spoken? (n) Answers spoken? (n)

\begin{tabular}{|c|c|c|c|c|c|c|c|c|}
\hline Level & Task Time & $\underline{\text { Stimulus }}$ & $\begin{array}{l}\text { Answer } \\
\text { Choices }\end{array}$ & Answers & Result & $\begin{array}{l}\text { Choices } \\
\text { Made }\end{array}$ & $\begin{array}{l}\text { Cues } \\
\text { Used }\end{array}$ & $\begin{array}{l}\text { Work } \\
\text { Time }\end{array}$ \\
\hline 1 & 2:16:43 PM & $\begin{array}{l}\text { piano, } \\
\text { blank }\end{array}$ & $\begin{array}{l}\text { guitar, } \\
\text { piano }\end{array}$ & piano & correct & 0 & 0 & :21 \\
\hline 1 & 2:17:08 PM & $\begin{array}{l}\text { melting, } \\
\text { blank }\end{array}$ & $\begin{array}{l}\text { melting, } \\
\text { glowing }\end{array}$ & melting & correct & 0 & 0 & :19 \\
\hline 1 & 2:17:30 PM & $\begin{array}{l}\text { easy, } \\
\text { blank }\end{array}$ & $\begin{array}{l}\text { easy, } \\
\text { difficult }\end{array}$ & easy & correct & 0 & 0 & :17 \\
\hline 1 & 2:17:49 PM & $\begin{array}{l}\text { she, } \\
\text { blank }\end{array}$ & $\begin{array}{l}\text { she, } \\
\text { he }\end{array}$ & she & correct & 0 & 0 & :13 \\
\hline
\end{tabular}




\section{B. Log Data Analyzed and Displayed in a Summary Daily Report}

User: GB1

Tuesday, March 11, 2014

Total Work Time: 55 minutes

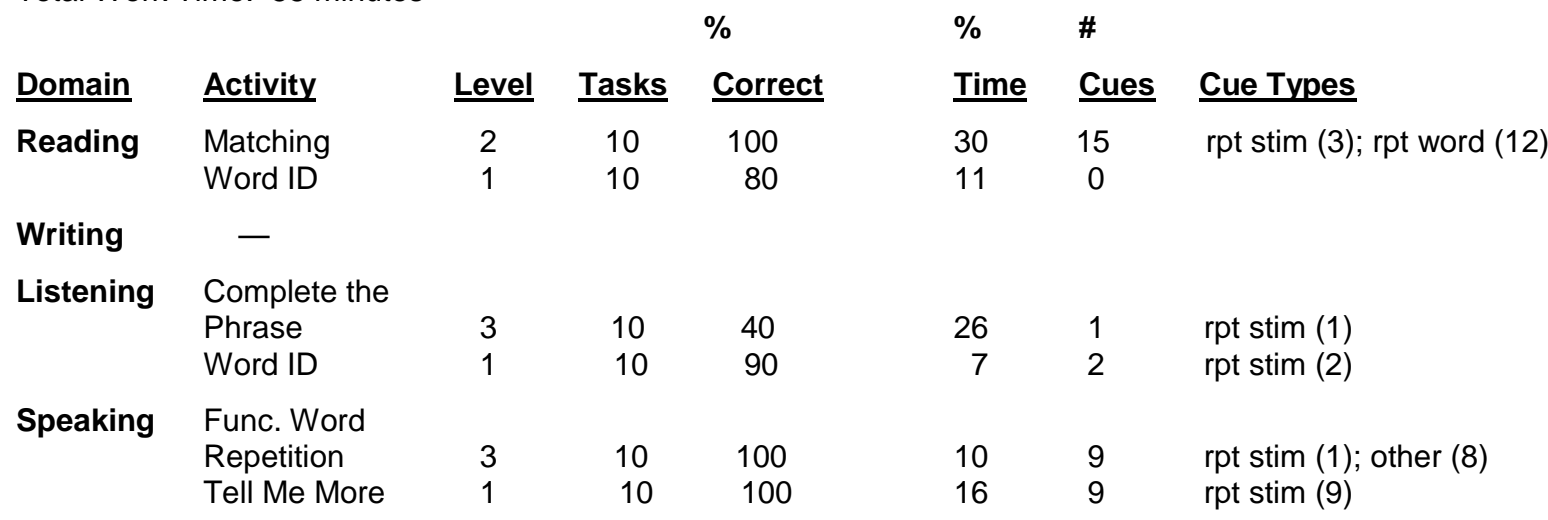

\section{COMPARISONS TO PREDECESSOR STUDY OUTCOMES}

From 1996 and 2001, Lingraphica managed a network of Language Care Center (LCC) treatment programs across the country whose therapeutic service delivery was similar in key ways to that of the current outcome study (Aftonomos et al. 1997, 1999, 2001; Steele et al. 2003, 2010). In particular, LCC clinical programs treated PWA well into the period of chronicity; they served PWA across the spectrum of aphasia diagnostic categories; they combined regularly scheduled, weekly therapy sessions with home practice that exploited Lingraphica's interactive, user-activated, multimodal therapy materials; and finally, they included assessments at intake and discharge using the WAB and the CETI. Key differences between LCC and current treatment were three: first, in the LCC programs, clinicians invariably conducted individual, in-person clinical therapy sessions with subjects, in contrast to the current outcome study the treating clinician worked with subjects sometimes in groups, sometimes individually, and without exception via computer technology; second, the LCC programs utilized earlier versions of our technology-based home practice materials on dedicated laptop computers, in contrast to the current study where those materials have been brought up to modern standards and are accessed from the Internet via a web browser; and third, in the LCC programs, subjects were persons who were typically re-starting speech therapy for the first time long after post-stroke rehabilitation had ended, in contrast to the current subjects, who - as members of a specialized aphasia center - regularly participate in community group treatment activities but do not have access to the 1:1 treatment opportunities or on-line therapy exercises provided in this study.

Because of the differences between participation times in the earlier published studies - in LCCs, ca. 20 to 22 weeks, depending on the diagnostic types - and therapy service delivery in the current study - 12 weeks, by design one is advised to look to congruence of patterns of relationships, rather than duplication of change magnitudes. From that perspective, outcomes documented in the current study are consonant with - and usefully extend - the major outcome patterns revealed by the LCC outcome analyses. For example, analysis of subjects treated in the LCC programs showed that a sizable minority of these PWA with chronic aphasia are candidates for reassignment to less severe diagnostic categories of aphasia upon discharge administration of the WAB. Specifically, in an earlier LCC subject sample of 46 , there were 14 subjects (30.4\%) who evolved to a less severe diagnostic category of aphasia by discharge, applying the criteria of an AQ improvement of more than 5 points (i.e., test-retest reliability threshold for the WAB) coupled with WAB reassignment upon discharge to a characteristically milder aphasia diagnostic category. In the current study, three of the nine subjects (33.3\%) underwent a similar change by those same criteria - a comparable percentage - and these three new cases mesh nicely with the framework established earlier. Quantitative relationships between scores at various assessment times and levels adhere to the same patterns also, in the earlier and present studies. For example, post-treatment scores are - as a general rule - greater than pre-treatment scores, indicating improved performance following treatment; and in the majority of such cases, both in the current as well as the LCC studies, those improvements are significant at the $p<$ .05 level. Additionally, in data both from the LCC studies and the current study, we find that improvements magnitudes are generally greater at the functional communication level than at the impairment level. 


\section{DISCUSSION}

This undertaking may be fairly adjudged to have achieved its two overarching goals, namely: (1) to demonstrate the practical feasibility using available telecommunication tools to deliver teletherapy to persons with chronic aphasia; and (2) to document and begin characterizing the clinical and other benefits of teletherapy, through an outcome study involving a demonstration sample of PWA.

Regarding goal (1) - technological significance - a feasibility study primarily helps set an agenda for future technical work. Specifically, while in the abstract it establishes the possibility of a general introduction of teletherapy offerings that are beneficial and attractive to potential clients, in the practical world it helps identify what issues need to be addressed to make such technologybased offerings workably sustainable - that is, operable, engaging, rewarding, affordable, maintainable, updatable, and extensible. The authors, in conjunction with other colleagues, purposefully intend to address these issues in future collaborations

Regarding goal (2) - clinical significance - the findings of this study first and foremost extend and enrich reports long appearing in the aphasiology literature, of benefits to persons with chronic aphasia from combining: (i) individualized 1-on-1 clinical sessions with SLPs using highly interactive, multimodal lingraphic treatment materials as a part of their treatment arsenal (Steele, 1995); and (ii) independent home practice by the PWA, who complete assigned exercises on technology platforms that exploit tight feedback loops through user control over exercise interactions (Aftonomos et al., 1997, 1999, 2001; Steele et al. 2003, 2010).

The current study complements that earlier work in several important ways. First, it shows that distance communication technologies on computers can be used to conduct the 1-on-1 treatment sessions, lifting any requirement that the clinician, the client, or both, travel to meet at some specified treatment venue. Second, it shows that remote group treatment sessions may stand in for a portion of remote 1-on-1 sessions, offering the promise of both more efficient use of clinician time and greater socialization opportunities for participating PWA. Third, it shows that independently utilized web-based therapy services, accessed either through a browser on a home computer or through an app downloaded onto a portable tablet, can be a viable way for the PWA to complete the assigned homework. In earlier studies, such technologies were simply not yet available, and participating PWA carried portable laptop computer platforms that were not Internetenabled. Fourth, it demonstrates an expanded range of PWA who are potential candidates for benefit from such services: the expanded range includes both people markedly deeper into the period of aphasic chronicity, and also those PWA who have been receiving considerable additional speech-language therapy in the immediately preceding years. And fifth, it broadens the number and types of outcome measures tracked: the earlier studies reported outcome results primarily at the impairment level (< WAB) and the functional communication level (<CETI); the current study additionally includes an SLP score reflecting reduction in cueing associated with successful client performance (< NOMS), a self-rating of communication confidence (<CCRSA), and a detailed post-participation survey on participant satisfaction levels with key aspects of the treatment program (<USS).

Differences of outcome changes in the current study vs. earlier LCC outcomes merit comment. Given differences in particulars of service delivery in the two contexts, one might reasonably expect outcome differences in the two settings. Specifically: (1) LCC clients were roughly 2 years postonset, on average; the current SCALE participants were closer to 5.6 years post-onset; (2) LCC clients had typically received no speech therapy since discharge from outpatient services 1.75 years or more previously; SCALE participants on average had been receiving speech therapy during the approximately 1.67 years immediately preceding this study; (3) treatment frequency for LCC clients - ca. 2 times per week - was greater than for SCALE participants, at 1.75 times per week; and (4) duration of participation was greater for LCC clients - ca. 20-22 weeks - than for the SCALE participants, with 12 weeks. Given these differences without exception advantaging LCC clients - one might anticipate greater gains in the LCC outcomes. At the impairment level, this is observed: LCC clients showed larger and statistically significant improvements across modalities, while SCALE participants' gains were modest and not statistically significant. At the level of functional communication, in contrast, gains in SCALE participants are closely comparable to those of LCC clients. It will require future research to show how further teletherapy might affect these relationships at the impairment and functional communication levels.

Some research suggests, however, that further significant gains would be expected with extended SCALE participation. The most directly applicable evidence comes from the growing body of research, in recent years, into the beneficial effects of massed practice for continuing advancement towards rehabilitation goals. To date, of course, published studies demonstrating these effects have involved subjects enrolled in formally designed research, in which completion of a specified amount of massed practice was obligatory. It is unclear whether subjects would have been engaged at such levels of intensity and duration, absent researcher insistence. Those formal studies, however, find a degree of practical support, with auspicious implications, in the outcome analyses of LCC data. There, clients' volitional home practice behaviors have suggested that properly designed rehabilitation technologies can play 
an important role in establishing and maintaining the desired massed practice behaviors. Aftonomos et al. (1997) analyzed volitional activity histories from automatically compiled lists that unobtrusively yet fully recorded user interface actions on the therapy platforms being used independently at home between clinical sessions. The analysis showed that users engaged in a wide variety of tasks, some that were assigned and others of their own devising; the mean time spent daily in these tasks was over two hours, some four times the assigned duration; and that some individuals sessions reached nearly seven hours. These data showed a tendency for long, uninterrupted, and varied engagement with the therapeutic technology. Of their own volition and for their own purposes, the clients were engaging in massed practice. Rewarding activities, stimulating interaction design, and effective progress feedback should strengthen these tendencies further.

It is worth drawing attention to how noteworthy the widespread additional mean improvements in these participants are. Not only are they - in the mean - very long post-onset, but as a practical matter they had been receiving weekly group therapy at SCALE for approximately two years immediately preceding this study. That group therapy, in addition, is quite similar in terms of overall philosophy, goals, and therapeutic approaches to those of the present study: both, for example, utilize techniques of Supported Communication, scripting, and sentence patterning described above; both also focus on providing skills and competencies for improving functional communication outside of the therapeutic setting.

The question thus arises of what might account for the additional bump. Certainly, definitive answers to this question will require future targeted research. But here we might offer preliminary thoughts - based on our experiences and observations in this study - on likely contributors to the additional improvements. Two obvious candidates come readily to mind. One is the addition and integration of independently accessed and used on-line TalkPath therapy materials, which can be accessed and used without limitation at participants' instance. In future publications, we intend to analyze homework practice patterns to see to what degree, and where, there are positive correlations between increased homework time, levels of challenge, types of activities, rates of success in these activities, and changes in assessment scores over time. Another potential factor is the exploitation of technologies to enrich the interactions possible during the remote face-to-face interactions - such as 'reverse scripting', in which a clinician captures and displays on the screen - and in real time - those words and phrases useful to advancing an ongoing communicative exchange. These can then be accessed later by the client for review, practice, and support. It would not be surprising if other, less obvious factors also contribute. Clearly future research will be required; but the two examples adduced here serve to exemplify how technologies of teletherapy can make new and useful capabilities available for exploitation to improve rehabilitation outcomes.

These results appear at a time of evolving understandings regarding effective, sustainable approaches to the rehabilitation and management of aphasia. An earlier, medically-oriented view of aphasia focused on the PWA as a patient with an illness to be treated and then discharged; but such views no longer hold sole sway. They have rightly been complemented by socially-oriented approaches, which view people with chronic aphasia as differently-abled individuals who benefit from ongoing, appropriate support for leading meaningful lives. This ongoing support may be of various types, and may address various needs - e.g., social, psychological, therapeutic, communicative, physical, emotional, financial. The newer positions represent a welcome expansion in our understandings of how best to serve and empower PWA.

As with any piece of research, this study's conclusions will be colored by its inherent biases and limitations. Among the former, participant biases require special attention. The current subject pool is not a randomly picked sample of persons with chronic aphasia, but rather a selected group of individuals who not only met our formal inclusion criteria, but who also had for considerable time been actively participating in an LPAA program that included group therapy. This suggests not only a strong sense of opportunity for improvement on their part, but points to high levels of initiative, focus, and persistence in exploiting those opportunities. How a more randomly selected group of PWA will benefit remains an open question. As an example of the latter - the study's limitations - we adduce the administration on only 10 of the 16 items of the CETI. A clearer and more coherent understanding of the benefits of this approach for functional communication awaits data from complete administrations of the CETI or comparable instrument. Such considerations, clearly, set the stage for future research.

Effective implementation of associated practices, however, remains a key challenge. In larger cities, one may find ongoing therapeutic programs in large, free-standing community-based treatment centers - such as SCALE in Baltimore - with highly effective service delivery; in smaller communities, subgroups of employees in - say - hospitals, or clinics, or academic departments may pursue implementation as possible; in yet other places, it remains but a future challenge. Needs abound, and resources are constrained. It is in this regard that the current study speaks most directly. The intelligent, creative exploitation of technology holds promise of extending therapeutic outreach to PWA, wherever they are. Teletherapy, in this context, should over time enjoy a growing adoption in the extended, cost-effective delivery of rehabilitative services to PWA; and the current study stands as a first demonstration of its practical feasibility, and as an initial characterization of its multiple benefits to persons with chronic aphasia. 


\section{DECLARATION OF INTERESTS}

Richard Steele and Lisa Haynes are employees of Lingraphica; Denise McCall and Allison Baird serve as consultants to Lingraphica.

\section{REFERENCES}

Aftonomos, L. B., Steele, R. D., \& Wertz, R. T. (1997). Promoting recovery in chronic aphasia with an interactive technology. Archives of Physical Medicine and Rehabilitation. 78, 841-846.

Aftonomos, L. B., Appelbaum, J. S., \& Steele, R. D. (1999). Improving outcomes for persons with aphasia in advanced community-based treatment programs. Stroke, 30, 1370-1379.

Aftonomos, L. B., Steele, R. D., Appelbaum, J. S., \& Harris, V. N. (2001). Relationships between impairment-level assessments and functional-level assessments in aphasia. Aphasiology. 15, 951-964.

Alarcon, N. B., \& Rogers, M. A. (2012). Supported Communication Intervention for Aphasia. Rockville, MD: American Speech-Language-Hearing Association.

ASHA - American Speech-Language-Hearing Association. (2003). National Outcomes Measurement System (NOMS); Adult Speech-Language Pathology User's Guide. Available from www.redocsoftware.com/files/customers/sllp-adultnoms-for-redoc-suite-v78.pdf

Babbitt, E. M., Heinemann, A. W., Semik, P., \& Cherney, L. R. (2011). Psychometric properties of the communication confidence rating scale for aphasia (CCRSA): Phase 2. Aphasiology, 25, 727-735.

Chapey, R., Duchan, J.F., Elman, R.J., Garcia, L.J., Kagan, A., Lyon, J.G., \& Simmons-Mackie, N. (2001). Life participation approach to aphasia. In R. Chapey (ed.). Language intervention strategies in aphasia and related neurogenic communication disorders $\left(4^{\text {th }}\right.$ ed.; pp. 235245). Philadelphia, PA: Lippincott Williams \& Wilkins

Cherney, L.R., Patterson, J.P., Raymer, A., Frymark, T., \& Schooling, T. (2008). Evidence-based systematic review: effects of intensity of treatment and constraintinduced language therapy for individuals with strokeinduced aphasia. Journal of Speech, Language, and Hearing Research, 51, 1282-1299.

Cherney, L.R., Babbitt, E.M., Semik, P., \& Heinemann, A.W. (2011). Psychometric properties of the Communication Confidence Rating Scale for Aphasia (CCRSA): Phase 1. Topics in Stroke Rehabilitation, 18, 352-360.
Cherney, L.R., \& vanVuuren, S. (2012). Telerehabilitation, Virtual Therapists, and Acquired Neurologic Speech and Language Disorders. Seminars in Speech and Language, 33, 243-257.

Duffy, J.R., Werven, G.W., \& Aronson, A.E. (1997). Telemedicine and the diagnosis of speech and language disorders. Mayo Clinic Proceedings, 72, 1116-1122.

Elman, R. J. (2007). The importance of aphasia group treatment for rebuilding community and health. Topics in Language Disorders, 27, 300-308.

Elman, R. J., \& Bernstein-Ellis, E. (1999). The efficacy of group communication treatment in adults with chronic aphasia. Journal of Speech, Language, and Hearing Research, 42, 411-419.

Frattali, C. M., ed. (1998). Measuring Outcomes in SpeechLanguage Pathology. New York, NY: Thieme.

Gaddie, A., Kearns, K., \& Yedor, K. (1991). A qualitative analysis of response elaboration training effects. In $\mathrm{T}$. E. Prescott (Ed.), Clinical Aphasiology (Vol. 21, pp. 171184). Austin, TX: PRO-ED

Georgeadis, A. C., Brenna, D. M., Barker, L. M., Baron, C. R. (2004). Telerehabilitation and its effect on story retelling by adults with neurogenic communication disorders. Aphasiology, 18, 639-652.

Hall, N., Boisvert, M., \& Steele, R. (2013). Telepractice in the assessment and treatment of individuals with aphasia: A systematic review. International Journal of Telerehabilitation, 5(1), 27-38.

Hatch, E., \& Farhady, H. (1982). Research design and statistics for applied linguistics. Rowley, MA: Newbury House Publishers.

Helm-Estabrooks, N., \& Ramsberger, G. (1986). Aphasia treatment delivered by telephone. Archives of Physical Medication and Rehabilitation, 67(1), 51-53.

Hill, A., Theodoros, D., Russell, T., Ward, E, \& Wootton, R. (2009). The effects of aphasia severity on the ability to assess language disorders via telerehabilitation. Aphasiology, 23, 627-642.

James, J. V. (1998). Tracking the right clues with exploratory data analysis. IEEE Spectrum, 38(8), 58-65.

Kagan, A. (1998). Supported communication for adults with aphasia: methods and resources for training conversation partners. Aphasiology, 12, 816-830.

Kearns, K. P. (1985). Response elaboration training for patient initiated utterances. In R.H. Brookshire (Ed.). Clinical Aphasiology (Vol. 15, pp. 196-204). Minneapolis, MN: BRK Publishers. 
Kertesz, A. (1982). Western Aphasia Battery. New York, NY: Grune \& Stratton.

Kertesz, A. (2006). Western Aphasia Battery-Revised. San Antonio, TX: PsychCorp.

Kiran, S., Des Roches, C., Balachandran, I., \& Ascenso, E. (2013). Validation of an iPad-based therapy for language and cognitive rehabilitation in individuals with brain damage. Poster presented at the 2013 Annual Convention, American Speech-Language-Hearing Association, Chicago, IL.

Lasker, J. P., Stierwalt, A. G., Spence, M., \& Calvin-Root, C. (2010). Using webcam interactive technology to implement treatment for severe apraxia: A case example. Journal of Medical Speech-Language Pathology, 18(4), 4-10.

Lee, J. B., Kaye, R. C., \& Cherney, L. R. (2009). Conversational script performance in adults with nonfluent aphasia: treatment intensity and aphasia severity. Aphasiology, 14, 885-897.

Lomas, J., Pickard, L., Bester, S., Elbard, H., Finlayson, A., \& Zoghaib, C. (1989). The communicative effectiveness index: development and psychometric evaluation of a functional measure for adult aphasia. Journal of Speech and Hearing Disorders. 54, 113124.

McCall, D. (2012). Steps to Success with Technology for Individuals with Aphasia. Seminars in Speech and Language. 33, 234-242.

Naeser, M. A. (1975). A structured approach teaching aphasics basic sentence types. British Journal of Disorders of Communication. 10, 70-76.

Pulvermüller, F., Neininger, B., Elbert, T., Mohr, B., Rockstroh, B., Koebbel, P., \& Taub, E. (2001). Constraint-induced therapy of chronic aphasia after stroke. Stroke. 32, 1621-1626.
Shewan, C., \& Kertesz, A. (1984). Validity and reliability characteristics of the Western Aphasia Battery (WAB). Journal of Speech and Hearing Disorders. 45, 308324.

Steele, R. D. (1995). Lingraphic methods in interface design. Proceedings of the International Workshop on Human Interface Technology IWHIT'95. Aizu, Japan: University of Aizu, 53-58.

Steele, R. D., Aftonomos, L. B., \& Munk, M. W. (2003). Evaluation and treatment of aphasia among the elderly with stroke. Topics in Geriatric Rehabilitation. 19(2), 98-108.

Steele, R. D., Aftonomos, L. B., \& Koul, R. K. (2010). Outcome improvements in persons with chronic global aphasia following the use of a speech-generating device. Acta Neuropsychologica. 8, 342-359.

Theodoros, D., Hill, A., Russell, T., Ward, E., \& Wootton, R. (2008). Assessing acquired language disorders in adults via the internet. Telemedicine and e-Health. 14, 552-557. DOI: 10.1089/tmj.2007.0091

Tukey, J. (1977). Exploratory data analysis. Reading, MA: Addison Wesley.

Vaughn, G. R. (1976). Tel-communicology: Health-care delivery system for persons with communicative disorders. ASHA, 18,13-17.

Wertz, R. T., Dronkers, N. F., Bernstein-Ellis, E., Sterling, L.K. Shubitowski, Y., Elman, R., Shenaut, G. K., Knight, R.T., \& Deal, J.L. (1992). Potential of telephonic and television technology for appraising and diagnosing neurogenic communication disorders in remote settings. Aphasiology, 6, 195-202.

Youmans, G., Holland, A., Munoz, M., \& Bourgeois, M. (2005). Script training and automaticity in two individuals with aphasia. Aphasiology, 10, 435-450. 
Appendix A. Items (N-10) Rated from the Communicative Effectiveness Index (CETI)*

1. Getting somebody's attention.

2. Getting involved in group conversations that are about him/her.

3. Giving yes and no answers appropriately.

4. Communicating his/her emotions.

5. Indicating that he/she understands what is being said to him/her.

6. Having coffee-time visits and conversations with friends and neighbors [around the bedside or at home].

9. Communicating physical problems such as aches and pains.

10. Having a spontaneous conversation [i.e., starting the conversation and/or changing the subject].

15. Participating in a conversation with strangers.

16. Describing or discussing something in depth.

${ }^{*}$ Items 7,8,11-14 were not rated.

Appendix B. Items Rated on the RIC - Communication Confidence Rating Scale for Aphasia (CCRSA) How confident are you ...

1. ... about your ability to talk with people?

2. ... about your ability to stay in touch with family and friends?

3. ... about your ability to follow news and sports on TV?

4. ... about your ability to follow movies on TV or in a theater?

5. ... about your ability to speak on the telephone?

6. ... that people understand you when you talk?

7. ... that people include you in conversations?

8. ... about your ability to speak for yourself?

9. ... that you can make your own decisions?

10. ... that you can participate in discussions about your finances? 
Appendix C. Items Included on the User Satisfaction Survey

\section{Remote Group Treatment}

\# 1. How satisfied are you with the group treatment using telehealth technologies?

\# 2. During group treatment, how well could you hear the clinician clearly?

\# 3. During group treatment, how well could you see the clinician clearly?

\# 4. How satisfied were you with the amount of time you participated in group?

\# 5. How enjoyable was it to participate in remote group treatment?

\# 6. How beneficial was it to participate in remote group treatment?

\# 7. How helpful was it to have SCALE staff assist during group treatment?

\section{Remote Individual Treatment}

\# 8. How satisfied are you with the 1-on-1 treatment using telehealth technologies?

\# 9. During 1-on-1 treatment, how well could you hear the clinician clearly?

\#10. During 1-on-1 treatment, how well could you see the clinician clearly?

\#11. How informative were the 1-on-1 treatment sessions for you?

\#12. How enjoyable was it to participate in remote 1-on-1 treatment?

\#13. How beneficial was it to participate in remote 1-on-1 treatment?

\#14. How helpful was it to have Lingraphica's remote technical assistance?

\section{Web-based Therapy Exercises}

\#15. How satisfied are you with the web-based therapy exercises?

\#16. How beneficial were the exercises that your SLP chose for you?

\#17. How beneficial were the exercises that you chose for yourself?

\#18. How convenient were the web-based exercises?

\#19. How well-suited were the exercise assignments to provide you benefit?

\#20. How helpful was technical assistance provided by weekly home support calls?

\#21. How helpful was home-practice for improving M/W group communications? 
International Journal of Telerehabilitation • telerehab.pittedu

\section{Work with the Therapist}

\#22. How connected with the therapist did you feel?

\#23. How valued, supported, and encouraged by the therapist did you feel?

\#24. How knowledgeable did the therapist seem to you?

\#25. How beneficially did the therapist set demand levels for you?

\#26. How enjoyable was your work with the therapist?

\#27. How important to your recovery was your therapist's encouragement? 